\title{
Application of WGM Resonances to the Measurement of the Temperature Increment of Ho and Ho-Yb Doped Optical Fibers Pumped at 1125 and 975 nm
}

\author{
Xavier Roselló-Mechó ${ }^{1, *(\mathbb{D})}$, Martina Delgado-Pinar ${ }^{1, *} \mathbb{D}$, Yuri O. Barmenkov ${ }^{2}$ (D), Alexander V. Kir'yanov ${ }^{2} \mathbb{D}$ \\ and Miguel V. Andrés ${ }^{1}$ (D) \\ 1 Department of Applied Physics and Electromagnetism-ICMUV, University of Valencia, C/Dr. Moliner 50, \\ 46100 Burjassot, Spain; miguel.andres@uv.es \\ 2 Photonics Department, Centro de Investigaciones en Óptica, Loma del Bosque 115, León 37150, Mexico; \\ yuri@cio.mx (Y.O.B.); kiryanov@cio.mx (A.V.K.) \\ * Correspondence: xavier.rosello@uv.es (X.R.-M.); Martina.Delgado@uv.es (M.D.-P.)
}

check for

updates

Citation: Roselló-Mechó, X.;

Delgado-Pinar, M.; Barmenkov, Y.O.;

Kir'yanov, A.V.; Andrés, M.V.

Application of WGM Resonances to the Measurement of the Temperature Increment of Ho and $\mathrm{Ho}-\mathrm{Yb}$ Doped Optical Fibers Pumped at 1125 and 975 nm. Sensors 2021, 21, 2094.

https://doi.org/10.3390/s21062094

Academic Editor: Saverio Avino

Received: 29 December 2020

Accepted: 15 March 2021

Published: 17 March 2021

Publisher's Note: MDPI stays neutral with regard to jurisdictional claims in published maps and institutional affiliations.

Copyright: (c) 2021 by the authors. Licensee MDPI, Basel, Switzerland. This article is an open access article distributed under the terms and conditions of the Creative Commons Attribution (CC BY) license (https:// creativecommons.org/licenses/by/ $4.0 /)$.

\begin{abstract}
Optical fiber characterization using whispering gallery mode resonances of the fiber itself has been demonstrated to be a powerful technique. In this work, we exploit the thermal sensitivity of whispering gallery mode resonances to characterize the pump-induced temperature increment in holmium doped and holmium-ytterbium codoped optical fibers. The technique relies on the measurement of the resonances' wavelength shift due to temperature variation as a function of the pump power. Holmium doped fibers were pumped to the second excited level ${ }^{5} \mathrm{I}_{6}$ of the $\mathrm{Ho}^{3+}$ ion using a laser diode at $1125 \mathrm{~nm}$ and ytterbium-holmium codoped fibers to the ${ }^{2} \mathrm{~F}_{5 / 2}$ level of the $\mathrm{Yb}^{3+}$ ion by a laser diode at $975 \mathrm{~nm}$. Our results demonstrate that pumping ytterbium-holmium codoped fibers at $975 \mathrm{~nm}$ results in dramatic thermal effects, producing a temperature increment two orders higher than that observed in holmium doped fibers pumped with a $1125 \mathrm{~nm}$ laser diode.
\end{abstract}

Keywords: whispering gallery modes; holmium; ytterbium; doped fibers; fiber characterization; $2 \mu \mathrm{m}$ fiber lasers

\section{Introduction}

The excitation of the azimuthal whispering gallery mode (WGM) resonances has been used to characterize different parameters in spherical and cylindrical microresonators. The wavelength shift of WGM resonances has been used to measure diameter fluctuations along a fiber [1,2], Pockel's coefficients [3], thermal effects in microspheres [4,5], erbium and ytterbium doped fibers [6], fiber Bragg gratings (FBGs) [7], and UV irradiated photosensitive fibers [8]. Some other techniques employed to measure temperature variations and thermal effects in fibers involve the use of FBGs [9], tapers [10,11], interferometric techniques [10-12], or Brillouin sensors [13]. The technique based in WGM is a non-invasive, non-destructive technique that allows characterizing special, pristine fibers without requiring any post-processing. The typical high $Q$-factor of the resonances $\left(10^{6}-10^{7}\right.$ in silica cylinders) allows achieving low detection limits $\left(0.06{ }^{\circ} \mathrm{C}\right.$ in our setup) and provides a large range of measurement without the ambiguity inherent to interferometric techniques. In addition, this technique provides an axial resolution below the mm level that allows measuring at localized points along a device, and it does not require long sections of fibers to perform the characterization.

Over the last two decades, advances in the performance of fiber lasers led to the adoption of this technology in several areas and applications in photonics, such as high power systems [14]. Most of the fiber lasers developed to date are based on silica fibers doped with three rare-earth elements: erbium $\left(\mathrm{Er}^{3+}\right)$, ytterbium $\left(\mathrm{Yb}^{3+}\right)$, and thulium $\left(\mathrm{Tm}^{3+}\right)$ [15]. The widespread use of these three chemical elements among the many others 
that have been investigated is due to different factors. Some of the key features that make these elements relevant are the following: Ytterbium shows conversion efficiencies up to $50 \%$, thus allowing its use for the manufacturing of high power fiber lasers. Erbium shows an emission band in the telecommunications wavelength range, while thulium's emission band is centered at $2 \mu \mathrm{m}$. Each dopant, or their combination with ytterbium, is exploited to develop novel light sources located in these two wavelength ranges, for several applications such as telecommunication, materials' processing, bio-imaging, etc. In turn, the applications of these specific doped fibers have driven the development of fiber-compatible components at the absorption and emission wavelengths, such as reliable pump diodes, isolators, fiber couplers, etc. In particular, it is worth highlighting that $\mathrm{Yb}$ and Er doped silica fibers show emission bands centered at $\sim 1 \mu \mathrm{m}$ and $\sim 1.5 \mu \mathrm{m}$, respectively, which meet the requirements for a huge variety of applications: in continuous wave (CW) high power lasers, in telecommunication technologies, in operational configurations for the generation of short giant pulses, etc. [16]. On the other hand, the fibers doped with $\mathrm{Tm}^{3+}$ present a broadband gain at $\sim 2 \mu \mathrm{m}$, a spectral region with increasing applications, for example, in the development of light sources for use in medical surgery, eye-safe technology (e.g., LIDAR), or spectroscopy [17]. As an alternative to $\mathrm{Tm}^{3+}$, holmium $\left(\mathrm{Ho}^{3+}\right)$ is an interesting option to develop fiber lasers centered in the spectral range above $\sim 2 \mu \mathrm{m}[18,19]$. The fibers doped with $\mathrm{Ho}^{3+}$ exhibit attractive properties for use in the design and fabrication of lasers: high efficiencies, a good power scaling, and an operational band spectrally located in a high transmission atmospheric window [20]. One of the main challenges with these types of fiber lasers is designing a proper pump system. The majority of reported holmium doped fiber lasers use an in-band pumped configuration by employing thulium doped fiber lasers [18] or a direct laser diode [21]. The wavelength of the pump source must be selected to match one of the two absorption bands of $\mathrm{Ho}^{3+}$, which are centered at $\sim 1.15 \mu \mathrm{m}$ and at $\sim 1.95 \mu \mathrm{m}[22,23]$. In order to allow pumping at optical wavelengths outside the absorption bands of $\mathrm{Ho}^{3+}$, codoped Ho fibers have been developed for application in fiber lasers, such as reported in [24-26]. Some designs have emerged by codoping the holmium fibers with other rare-earth ions, such as $\mathrm{Yb}^{3+}$ [24]. These variants enable the employment of pump sources at wavelengths out of the absorption bands of $\mathrm{Ho}^{3+}$ [25].

As mentioned, one of the main applications of the fibers doped with $\mathrm{Ho}^{3+}$ is the development of high power lasers beyond $2 \mu \mathrm{m}$, both CW and pulsed, which require significantly large pump powers [27]. Due to the non-radiative transitions that may occur in the active medium, this leads to a temperature increment of the fibers when they are under the operational regime. The heating may affect the performance of the fiber laser, for example by shifting the spectral position of the fiber Bragg gratings (FBGs) included in the setup to provide the optical feedback in a Fabry-Pérot laser scheme and by changing the absorption and emission spectra of active fibers. Therefore, the study of the pump-induced heating suffered by doped fibers is a topic of interest [6].

In this work, we employ a technique based on the temperature sensitivity of the WGM resonances in order to characterize the temperature increment of doped fibers. In silica microresonators with diameters comparable to those of optical fibers, the optical field of the WGMs is mainly located inside the resonator, bounded to the outer surface; thus, they will be highly sensitive to variations in the physical properties of the microresonator material. Since these microresonators exhibit intrinsically low losses and the guiding mechanism is the total internal reflection, the WGM resonances show extremely high Q-factors [28], enabling the measurement of small variations of the microresonator parameters, with a low detection limit. Another important advantage of the technique is that the WGM resonances are excited at a given point on the fiber, which enables monitoring the variations along the fiber. In the case of a thermal characterization, the temperature profile can be measured with high precision [7]. We propose to exploit the WGM measurement technique to determine the influence of the pump-induced heating on different parameters such as the concentration of $\mathrm{Ho}^{3+}$, the introduction of $\mathrm{Yb}^{3+}$ as a codopant, and the use of two different pump wavelengths ( $975 \mathrm{~nm}$ and $1125 \mathrm{~nm}$ ). 


\section{Theoretical Description}

\subsection{WGM Thermal Sensitivity}

The spectral position of the WGM resonances is set by the refractive index of the resonator cladding material and its diameter. Both parameters depend on the temperature and lead to heating-induced shifts of the resonance. The relative wavelength shift, $\Delta \lambda$, of the WGM resonances as a function of a given temperature increment, $\Delta T$, can be expressed as follows:

$$
\frac{\Delta \lambda}{\lambda}=\left(\frac{1}{R} \frac{d R}{d T}+\frac{1}{n_{\mathrm{eff}}} \frac{d n_{\mathrm{eff}}}{d T}\right) \Delta T,
$$

where $\lambda$ is the resonant wavelength of the unperturbed resonator, $R$ the radius of the fiber, and $n_{\text {eff }}$ the effective refractive index of the WGMs. This shift is ruled by the thermooptic effect and the thermal expansion coefficient of the material. For cladding-silica fibers, like the ones treated in this work, the shift rate of the resonances was measured in previous works to be $8.2 \mathrm{pm} /{ }^{\circ} \mathrm{C}$, and it allows correlating the temperature increment with the WGM resonances' shift [6]. Moreover, accurate numerical simulations determined that the different WGM resonances in the vicinity of $1.55 \mu \mathrm{m}$ show the same shift rates with temperature, simplifying the utility of the technique since the modal labeling of the resonances is not necessary [29]. Finally, since the WGM resonances are excited at a given point of the microresonator, the use of these modes enables axial characterization of the thermal profile of the fiber under test with a spatial resolution limited by the axial extension of the WGMs, which for our devices is $\sim 200 \mu \mathrm{m}$ [28].

\subsection{Energy Level Diagram of the Yb/Ho Codoped Fibers}

For this work, we investigated the thermal effects in two $\mathrm{Ho}^{3+}$ doped fibers. Figure 1 presents the energy levels of $\mathrm{Yb}^{3+}$ (Figure 1a), $\mathrm{Ho}^{3+}$ (Figure 1b), and the energy transfer mechanism between both systems. The first fiber we investigated was an $\mathrm{Ho}^{3+}$ fiber without any other dopants. In this case, we exploited the ${ }^{5} \mathrm{I}_{6}$ absorption band of $\mathrm{Ho}^{3+}$ to pump the fiber; this absorption band is centered at $\sim 1150 \mathrm{~nm}$ [30]. We employed an in-band configuration, by pumping at $1125 \mathrm{~nm}$. The second fiber included $\mathrm{Yb}^{3+}$ as a codopant, together with $\mathrm{Ho}^{3+}$. In this case, we pumped outside the absorption bands of $\mathrm{Ho}^{3+}$, at $975 \mathrm{~nm}$, by exploiting the ${ }^{2} F_{5 / 2}$ band of ytterbium (see Figure 1a) and the consequent energy transfer mechanism to the ${ }^{5} \mathrm{I}_{6}$ band of $\mathrm{Ho}^{3+}$ [26].

Figure 1 shows a simplified scheme of the energy levels of the ion multi-system $\mathrm{Ho}^{3+} / \mathrm{Yb}^{3+}$ and the processes involved to generate lasing at $>2 \mu \mathrm{m}$. For a $975 \mathrm{~nm}$ pump wavelength, the $\mathrm{Yb}^{3+}$ ions in the ground state, ${ }^{2} F_{7 / 2}$, are excited to the energy level ${ }^{2} F_{5 / 2}$. Part of the energy is then transferred to the $\mathrm{Ho}^{3+}$ ions, resulting in the excitation to the ${ }^{5} I_{6}$ energy level. Then, after a non-radiative multiphonon relaxation to the ${ }^{5} I_{7}$ energy level, photons with a wavelength beyond $2 \mu \mathrm{m}$ are emitted. The second option consists of using $1125 \mathrm{~nm}$ to pump the active medium, which results in a direct excitation of $\mathrm{Ho}^{3+}$ ions from the ground level ${ }^{5} I_{8}$ to the second excited level ${ }^{5} I_{6}$. Again, a non-radiative relaxation occurs in the decay to the ${ }^{5} I_{7}$ (laser) level, which ends up lasing at $2 \mu \mathrm{m}$ in the decay to the ground state. The complete description of the energy levels in the $\mathrm{Yb} / \mathrm{Ho}$ system and the processes during the pump illumination can be found in detail in [26]. The non-radiative processes that are present in the $\mathrm{Ho}^{3+} / \mathrm{Yb}^{3+}$ subsystems are responsible for the temperature increment suffered by the doped fibers. It is important to note that the quantum efficiency of the radiative decay from the laser level is rather low $(\sim 7-10 \%)$ due to partially multiphonon relaxation [31,32], which results in additional thermal loss. 


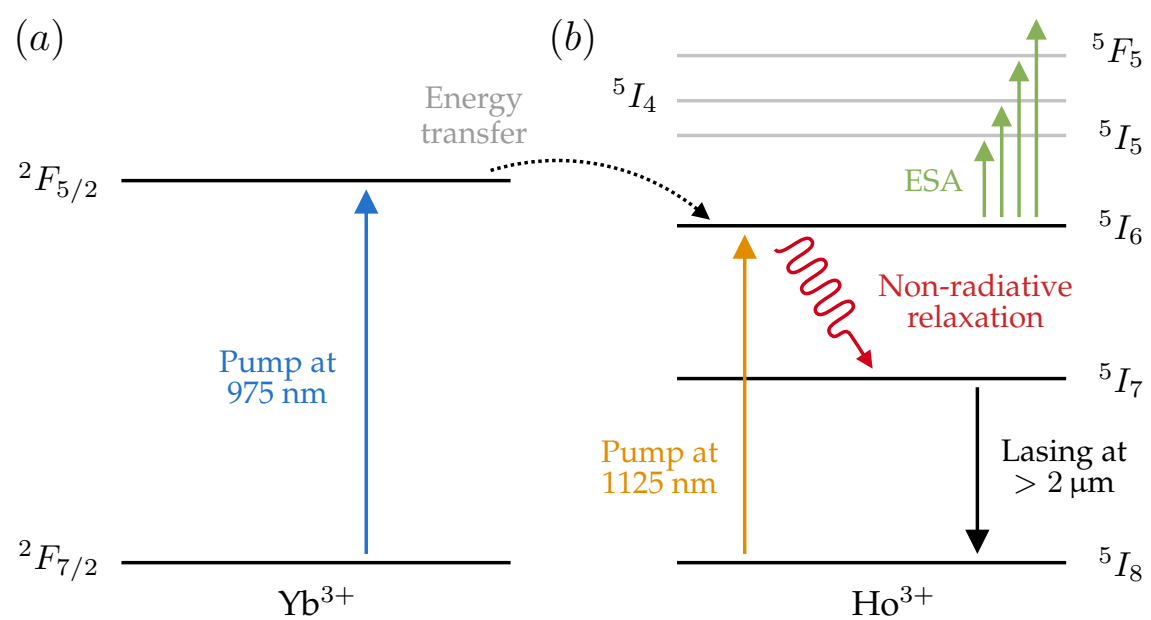

Figure 1. Simplified diagram of the energy levels of (a) $\mathrm{Yb}^{3+}$ and (b) $\mathrm{Ho}^{3+}$ ions, as well as the processes involved to generate lasing beyond $2 \mu \mathrm{m}$ with pump signals at 975 and $1125 \mathrm{~nm}$.

\section{Experimental Procedure}

Figure 2 shows a scheme of the experimental setup employed both to pump the doped fibers and to characterize the response of the WGM resonances. To excite the WGM resonances in the doped fibers, which play the role of the microresonators, we used an auxiliary tapered silica fiber of a $2 \mu \mathrm{m}$ waist and a $5 \mathrm{~mm}$ length [33]. We tapered the diameter of a conventional optical fiber by employing a fuse and pull technique [34]. The taper and the microresonator were placed perpendicularly. The distance between taper and resonator was controlled by a 3 axis flexure stage; although, in order to prevent undesired noise in the measurements, both elements were placed in contact. Moreover, the taper was swept along the doped fibers to characterize their thermal profile. The observed resonances showed a typical $3 \mathrm{~dB}$ linewidth $204 \mathrm{fm}$, corresponding to a Q-factor of $(7.61 \pm 0.05) \cdot 10^{6}$. Figure $3 \mathrm{a}, \mathrm{b}$ shows an illustrative example of the wavelength shift suffered by the WGM resonances as the temperature of the optical fiber increases, to illustrate the operational principle of our example.

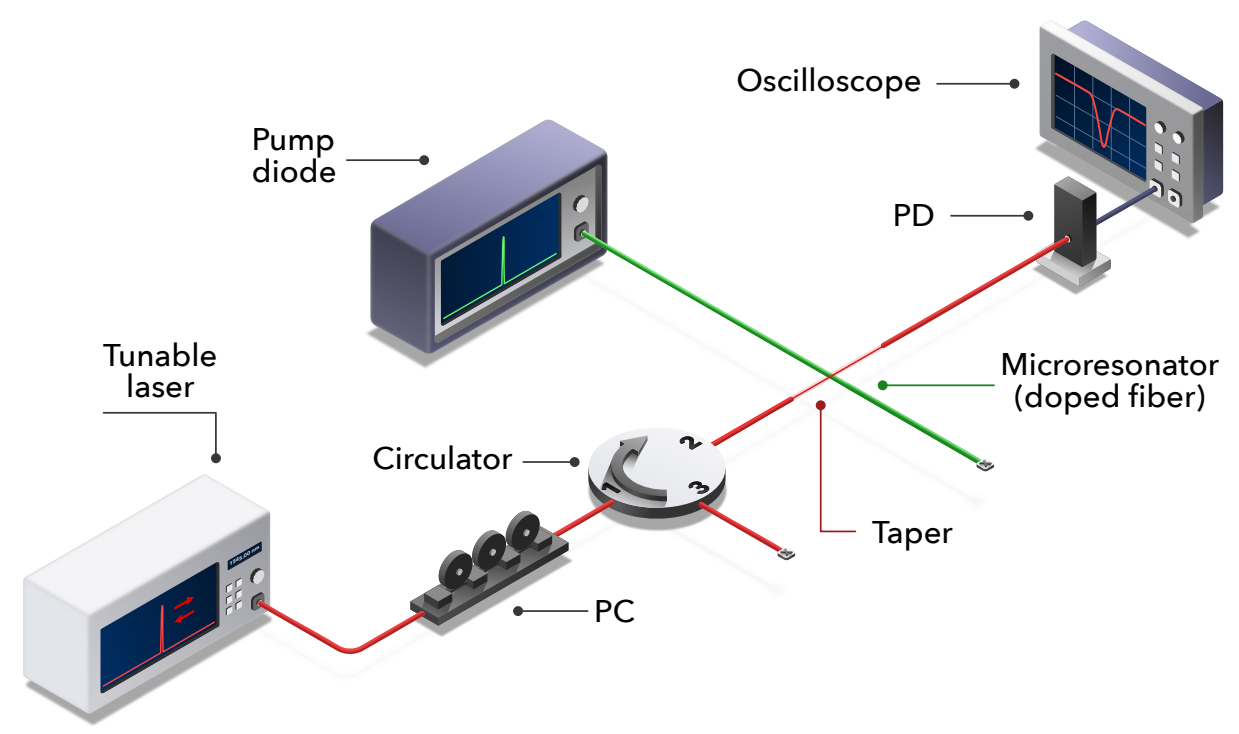

Figure 2. Scheme of the experimental setup employed to characterize the temperature increment by means of the whispering gallery modes (WGMs). PD, photodiode; PC, polarization controller. 
To excite the WGM resonances, we employed a tunable, linearly polarized laser (linewidth $<300 \mathrm{kHz}$ ) with a tuning range that covers 1515 to $1545 \mathrm{~nm}$. By employing the piezoelectric tuning facility of the laser, we performed a continuous scanning of the emitted signal. A polarization controller (PC) was placed to optimize the excitation of one of the WGM polarizations, either TE (transversal electric) or TM (transversal magnetic). Since the thermo-optic effect is intrinsically isotropic, both polarizations respond identically to a given heating, that is a given value of the pump power. A circulator was placed before the tapered fiber to measure the WGM reflected signal as an alternative to the measurement of the notches in transmission. The transmitted signal of the taper was measured by means of a photodiode (PD), whose output electric signal was registered by an oscilloscope (OSC) synchronized with the signal that drives the wavelength shift of the laser. It is noteworthy that the optical field of the WGMs is strongly located in the cladding-air interface, mostly within the resonator, in a shell of about $3 \mu \mathrm{m}$ in width for the fundamental radial order mode [35]. Since the dopants are in the core of the fiber, the WGM field distribution does not overlap with them, and then, it does not affect the excitation of the $\mathrm{Ho}^{3+}$ and $\mathrm{Yb}^{3+}$ ions. On the other hand, although the source of the heating is located in the core of the doped fiber, it distributes over the transversal section of the fiber with the result of a mostly uniform transversal temperature profile, where the difference of temperature between the core of the fiber and the vicinity of the cladding-air interface is smaller than 1.5\% [36].

The pump signal launched through the doped fiber was provided by two pigtailed, single-mode, CW laser diode sources with a maximum power of $400 \mathrm{~mW}$ operating at different wavelength: (i) at $1125 \mathrm{~nm}$ and (ii) at $975 \mathrm{~nm}$. We characterized three different types of home-made doped fibers: two holmium doped fibers (HDFs) with different concentrations (doping level ratio of HDF2/HDF1 1.5) and an ytterbium-holmium codoped fiber (YHDF). The absorption losses of HDF1 and HDF2 at $1125 \mathrm{~nm}$ are $\sim 3.6 \mathrm{~dB} / \mathrm{m}$ and $\sim 6.7 \mathrm{~dB} / \mathrm{m}$, respectively. For the $\mathrm{YHDF}$, at $978 \mathrm{~nm}$, it presents $\sim 2100 \mathrm{~dB} / \mathrm{m}$, while at $1125 \mathrm{~nm}$, it is $\sim 7 \mathrm{~dB} / \mathrm{m}$, which is similar to the loss of HDF2. Sections of a few centimeters long of doped fibers were studied in this work. The fibers under test were spliced to a Fibercore SM980 and to the pigtailed pump diode. The temperature increment was measured at $\sim 1 \mathrm{~mm}$ after the splice. The detailed information about the fiber parameters, dopant concentrations, and the process of fabrication can be found in $[24,30]$ for HDFs and the YHDF, respectively.
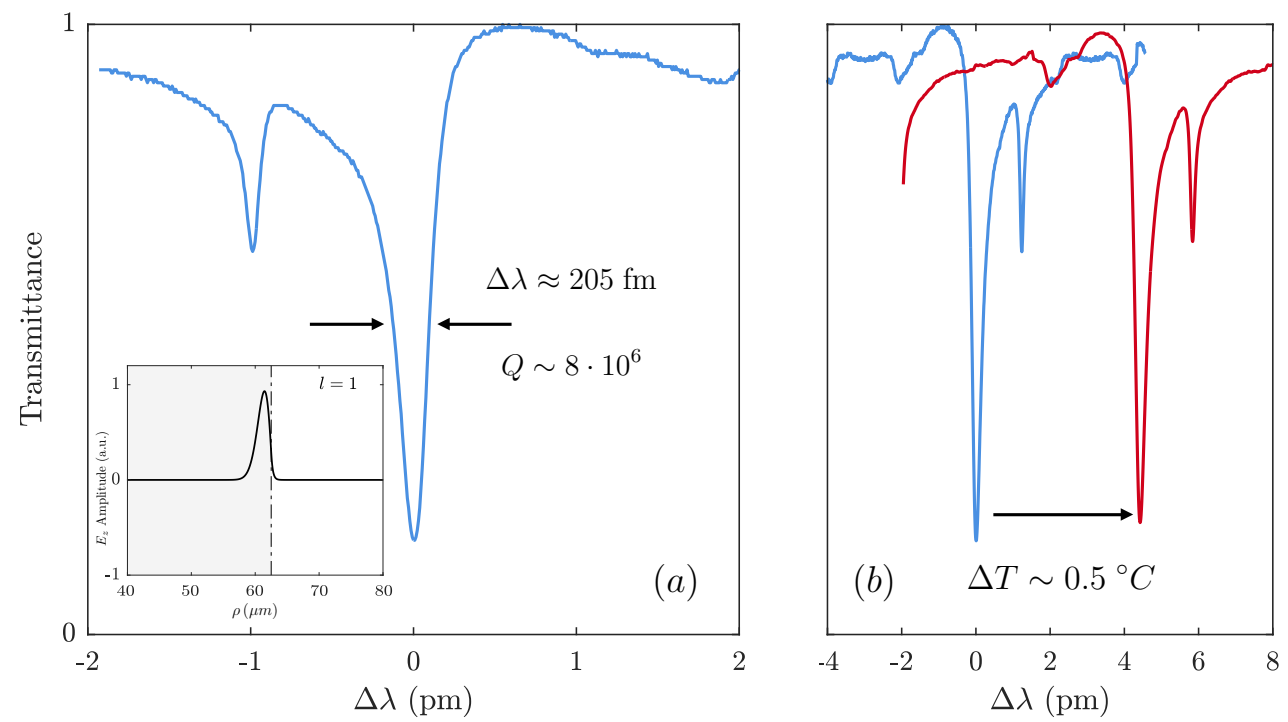

Figure 3. (a) Transmission trace of a typical WGM resonance (inset: radial profile of a fundamental mode of a WGM resonance ( $l=1$ and $m=354)$; (b) illustrative example of the wavelength shift suffered by the resonances for a temperature increment of $\Delta T=0.5^{\circ} \mathrm{C}$. 


\section{Results and Discussion}

First, we measured the thermal shift of the WGM resonances excited in the HDFs at $\sim 1 \mathrm{~mm}$ after the splice, when the $1125 \mathrm{~nm}$ pump signal was launched through them. Figure 4 shows the temperature increment in HDF1 and HDF2 as a function of the launched power. The heating rate of $\mathrm{HDF} 1$ was $11.37 \pm 0.14^{\circ} \mathrm{C} / \mathrm{W}$, while the rate for $\mathrm{HDF} 2$ was $18.16 \pm 0.18^{\circ} \mathrm{C} / \mathrm{W}$. HDF2 suffered a temperature increment $\sim 1.6$ times larger than HDF1. This result is in concordance with the concentration ratio of the dopant used for the fabrication of the fibers, which is HDF2/HDF1 1.5. As can be observed in Figure 4, in the power range studied, the heating showed a linear trend with the pump power, and there was no sign of saturation or nonlinearity. Exploiting the capability to measure the thermal profile of the fibers, we characterized the temperature increment at different positions along the HDFs. Along a length of $15 \mathrm{~mm}$ from the splice between the HDF and the SMF980 fiber used for pump delivery, the heating rate showed the same linear trend, and no significant variations were observed. This allowed us to assume that the pump of the fibers was uniform along the sections of fiber under study, for this length of the resonators/fibers.

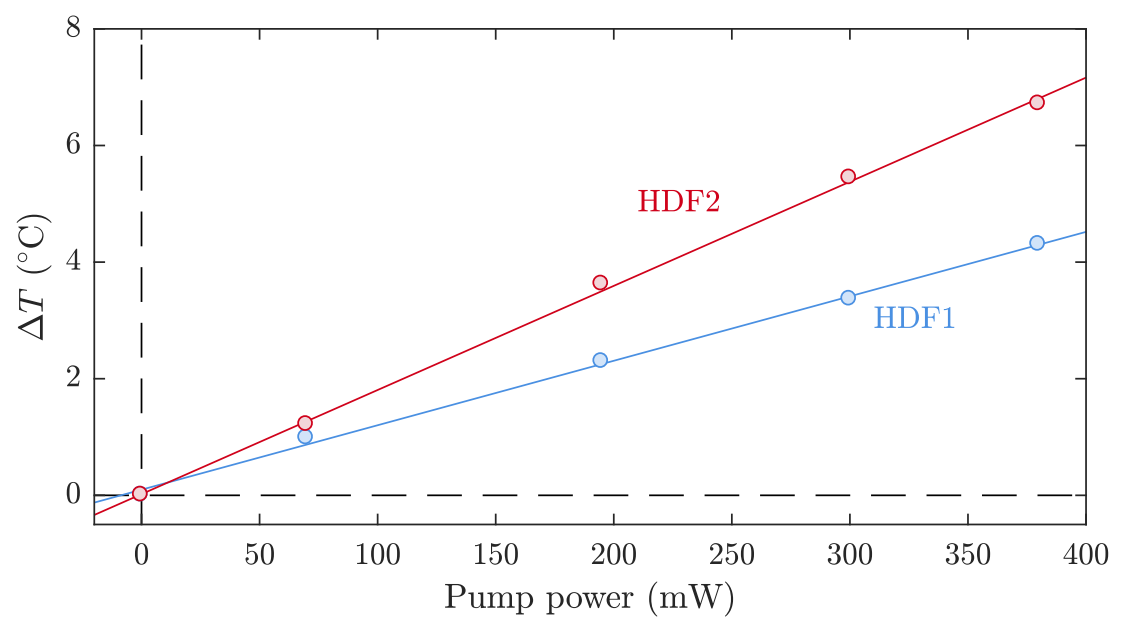

Figure 4. Measurement of the temperature increment of Holmium Doped Fiber 1 (HDF1) and HDF2 as a function of the pump signal power. Pump wavelength centered at $1125 \mathrm{~nm}$.

Figure 5a shows the temperature increment of the YHDF as a function of the launched power at $1125 \mathrm{~nm}$. The heating rate was $21.4 \pm 0.2^{\circ} \mathrm{C} / \mathrm{W}$, showing a linear trend with no evidence of saturation or nonlinearity in the studied power range. Since the concentration of $\mathrm{Ho}^{3+}$ in the YHDF is similar to that in HDF2, the temperature increments in these two fibers are comparable. Then, the same section of the YHDF was pumped at $975 \mathrm{~nm}$, exploiting the indirect excitation of the multi-system $\mathrm{Ho} / \mathrm{Yb}$. Figures 1 and $5 \mathrm{~b}$ show that the temperature increment experienced by the YHDF was much greater than for the previous scenario. At $400 \mathrm{~mW}$ of pump power, the fiber reached a temperature increment that exceeded $200^{\circ} \mathrm{C}$.

The heating strongly deviated from a linear response: the best fit was obtained using a standard formula for saturating process $\Delta T=k P /\left(P+P_{\text {sat }}\right)$, where $k$ is a coefficient, $P$ is the pump power, and $P_{\text {sat }}$ is the saturating pump power. The formula was obtained on the assumption that the main limiting factor for the temperature increase is saturation of the population of $\mathrm{Yb}^{3+}$ ions in the excited state, which limits energy transfer from $\mathrm{Yb}^{3+}$ ions to $\mathrm{Ho}^{3+}$ ions. By fitting the experimental data to this formula, the saturation pump power in the YHDF at $975 \mathrm{~nm}: P_{\text {sat }}=460 \mathrm{~mW}$ (value of the coefficient: $k \approx 514$ ) can be obtained. It was also observed that the local heating rates decreased as the pump power increased. In particular, the heating rate around $50 \mathrm{~mW}$ of pump power was three times the value around $300 \mathrm{~mW}$ of pump power (the local slopes' values of the curve are indicated next to the fitting curve in Figure 5b). For this fiber, we observed a significant dependence of the heating as a function of the axial position, as a result of the high absorption coefficient 
of the fiber at this wavelength. We measured the heating at different points along the fiber and concluded that the pump power was mostly absorbed after $5 \mathrm{~cm}$. Thus, we set the position for measurements shown in Figure $5 \mathrm{~b}$ at $1 \mathrm{~mm}$ from the splice of the YHDF and a section of SM980 (the fiber used for pump delivery) and carefully repeated every characterization at the same position.
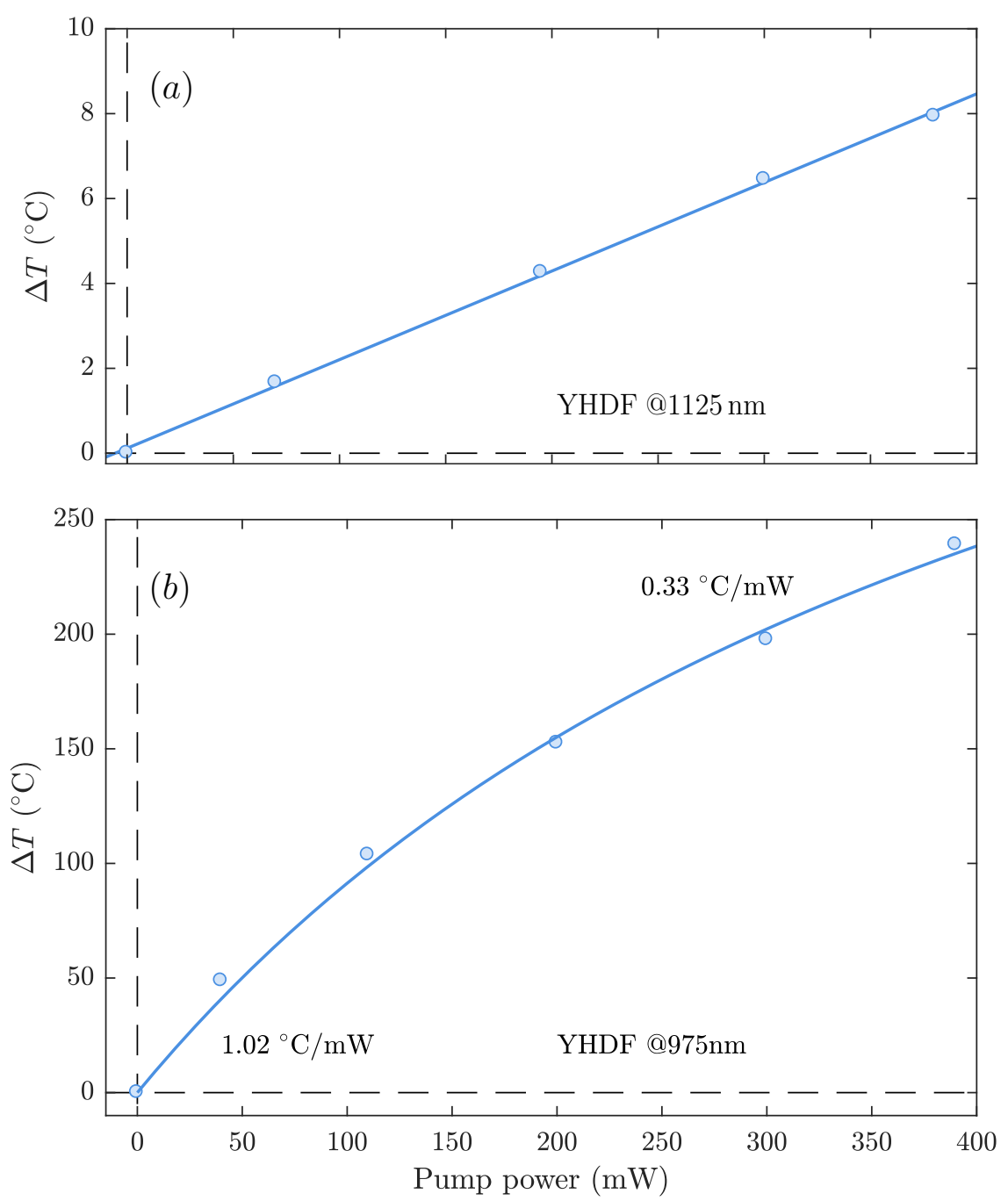

Figure 5. Temperature increment of the ytterbium-holmium codoped fiber (YHDF) as function of the pump signal at two different wavelengths: (a) at $1125 \mathrm{~nm}$; (b) at $975 \mathrm{~nm}$. Circles and curves show experimental points and fits, respectively.

Therefore, when the YHDF is pumped with a signal at $975 \mathrm{~nm}$, the induced thermal effects can be critical. In other experiments involving $\mathrm{Yb} / \mathrm{Ho}$ codoped fibers pumped around $1 \mu \mathrm{m}$, the authors employed a pump source at $1064 \mathrm{~nm}$ where the absorption coefficient was dramatically smaller ( $2100 \mathrm{~dB} / \mathrm{m}$ at $978 \mathrm{~nm}$ and $\sim 3.4 \mathrm{~dB} / \mathrm{m}$ at $1064 \mathrm{~nm})$ [24].

\section{Conclusions}

The WGM technique employed in this work allowed us to perform a thermal characterization of the pump-induced heating suffered by holmium doped and ytterbium-holmium codoped silica fibers. This technique enables the characterization of fibers with different concentrations and types of dopants and their response to pump signals at different wavelengths. The HDFs pumped at $1125 \mathrm{~nm}$ showed a direct correlation between the heating and the concentration of dopant. On the other hand, the YHDF showed a critical temperature increment when pumped at $975 \mathrm{~nm}$, exceeding $200^{\circ} \mathrm{C}$ for $400 \mathrm{~mW}$ of pump 
power. The information from the thermal characterization might be used in the design of new active $\mathrm{Ho} / \mathrm{Yb}$ fibers, a key component in the manufacturing of all-fiber laser cavities emitting beyond $2 \mu \mathrm{m}$, in order to study different concentrations of rare-earth ions to enhance the radiative processes and reduce the pump-induced heating important for lasers' optimization.

Author Contributions: X.R.-M. designed the experiment, performed the measurements, carried out the analysis of the results, and wrote the paper. M.D.-P. designed the experiment and reviewed the results and the manuscript. Y.O.B. and A.V.K. reviewed the results and the manuscript and proposed the mathematical model for the nonlinear heating. M.V.A. designed the experiment, reviewed the results and the manuscript, and was responsible for the funding. All authors read and agreed to the published version of the manuscript.

Funding: This research was co-funded by the Ministerio de Ciencia, Innovación y Universidades of Spain and Fondo Europeo de Desarrollo Regional (FEDER) (Ref. PID2019-104276RB-I00) and the Generalitat Valenciana (Ref: PROMETEO/2019/048). X. Roselló-Mechó's contract is funded by the FPI program (MINECO, Spain, BES-2014-068607).

Institutional Review Board Statement: Not applicable.

Informed Consent Statement: Not applicable.

Data Availability Statement: Not applicable.

Conflicts of Interest: The authors declare no conflict of interest.

\section{References}

1. Sumetsky, M.; Dulashko, Y. Radius variation of optical fibers with angstrom accuracy. Opt. Lett. 2010, 35, 4006. [CrossRef]

2. Birks, T.A.; Knight, J.C.; Dimmick, T.E. High-resolution measurement of the fiber diameter variations using whispering gallery modes and no optical alignment. IEEE Photonics Technol. Lett. 2000, 12, 182-183. [CrossRef]

3. Roselló-Mechó, X.; Delgado-Pinar, M.; Díez, A.; Andrés, M.V. Measurement of Pockels' coefficients and demonstration of the anisotropy of the elasto-optic effect in optical fibers under axial strain. Opt. Lett. 2016, 41, 2934. [CrossRef]

4. Guan, G.; Arnold, S.; Otugen, M.V. Temperature Measurements Using a Microoptical Sensor Based on Whispering Gallery Modes. AIAA J. 2006, 44, 2385-2389. [CrossRef]

5. Ma, Q.; Rossmann, T.; Guo, Z. Temperature sensitivity of silica micro-resonators. J. Phys. D Appl. Phys. 2008, $41,245111$. [CrossRef]

6. Rivera-Perez, E.; Villegas, I.L.; Diez, A.; Andres, M.V.; Cruz, J.L.; Rodriguez-Cobos, A. Measurement of Pump-Induced Temperature Increase in Doped Fibers Using Whispering-Gallery Modes. IEEE Photonics Technol. Lett. 2013, 25, $2498-2500$. [CrossRef]

7. Delgado-Pinar, M.; Villegas, I.L.; Díez, A.; Cruz, J.L.; Andrés, M.V. Measurement of temperature profile induced by the optical signal in fiber Bragg gratings using whispering-gallery modes. Opt. Lett. 2014, 39, 6277. [CrossRef] [PubMed]

8. Roselló-Mechó, X.; Delgado-Pinar, M.; Cruz, J.L.; Díez, A.; Andrés, M.V. Measurement of UV-induced absorption and scattering losses in photosensitive fibers. Opt. Lett. 2018, 43, 2897. [CrossRef]

9. Kersey, A.; Berkoff, T. Fiber-optic Bragg-grating differential-temperature sensor. IEEE Photonics Technol. Lett. 1992, 4, 1183-1185. [CrossRef]

10. Kou, J.L.; Feng, J.; Ye, L.; Xu, F.; Lu, Y.Q. Miniaturized fiber taper reflective interferometer for high temperature measurement. Opt. Express 2010, 18, 14245. [CrossRef]

11. Monzon-Hernandez, D.; Minkovich, V.; Villatoro, J. High-temperature sensing with tapers made of microstructured optical fiber. IEEE Photonics Technol. Lett. 2006, 18, 511-513. [CrossRef]

12. Davis, M.; Digonnet, M. Measurements of thermal effects in fibers doped with cobalt and vanadium. J. Light. Technol. 2000, 18, 161-165. [CrossRef]

13. Coscetta, A.; Catalano, E.; Cerri, E.; Zeni, L.; Minardo, A. A Dual-Wavelength Scheme for Brillouin Temperature Sensing in Optically Heated Co2x-Doped Fibers. IEEE Sens. J. 2020, 20, 1349-1354. [CrossRef]

14. Zervas, M.; Codemard, C. High Power Fiber Lasers: A Review. IEEE J. Sel. Top. Quantum Electron. 2014, 20, 219-241. [CrossRef]

15. Dragic, P.D.; Cavillon, M.; Ballato, J. Materials for optical fiber lasers: A review. Appl. Phys. Rev. 2018, 5, 041301. [CrossRef]

16. Richardson, D.J.; Nilsson, J.; Clarkson, W.A. High power fiber lasers: Current status and future perspectives. J. Opt. Soc. Am. B 2010, 27, B63. [CrossRef]

17. Nufern, B.S.; Dong, L. Fiber lasers. In Handbook of Solid-State Lasers; Elsevier: Amsterdam, The Netherlands, 2013 ; pp. 403-462.

18. Kurkov, A.; Dianov, E.; Medvedkov, O.; Ivanov, G.; Aksenov, V.; Paramonov, V.; Vasiliev, S.; Pershina, E. Efficient silica-based $\mathrm{Ho}^{3+}$ fibre laser for $2 \mu \mathrm{m}$ spectral region pumped at $1.15 \mu \mathrm{m}$. Electron. Lett. 2000, 36, 1015. [CrossRef]

19. Jackson, S. Midinfrared Holmium Fiber Lasers. IEEE J. Quantum Electron. 2006, 42, 187-191. [CrossRef] 
20. Friebele, E.J.; Askins, C.G.; Peele, J.R.; Wright, B.M.; Condon, N.J.; O'Connor, S.; Brown, C.G.; Bowman, S.R. Ho doped fiber for high energy laser applications. In Fiber Lasers XI: Technology, Systems, and Applications; Ramachandran, S., Ed.; SPIE: Bellingham, WA, USA, 2014.

21. Jackson, S.D.; Bugge, F.; Erbert, G. Directly diode-pumped holmium fiber lasers. Opt. Lett. 2007, 32, 2496. [CrossRef]

22. Kurkov, A.S.; Dvoyrin, V.V.; Marakulin, A.V. All-fiber $10 \mathrm{~W}$ holmium lasers pumped at $\lambda=1.15 \mu \mathrm{m}$. Opt. Lett. 2010, 35, 490. [CrossRef]

23. Hemming, A.; Bennetts, S.; Simakov, N.; Davidson, A.; Haub, J.; Carter, A. High power operation of cladding pumped holmium doped silica fibre lasers. Opt. Express 2013, 21, 4560. [CrossRef] [PubMed]

24. Kir'yanov, A.V.; Minkovich, V.P.; Barmenkov, Y.O. All-Fiber 2.05- $\mu$ m Continuous-Wave Ytterbium-Holmium Laser Pumped at $1.064 \mu \mathrm{m}$. IEEE Photonics Technol. Lett. 2014, 26, 1924-1927. [CrossRef]

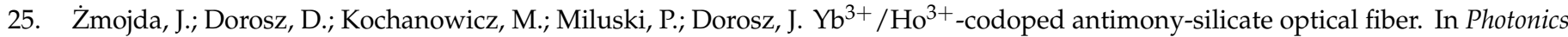
Applications in Astronomy, Communications, Industry, and High-Energy Physics Experiments 2012; Romaniuk, R.S., Ed.; SPIE: Bellingham, WA, USA, 2012.

26. Kir'yanov, A.V.; Barmenkov, Y.O.; Minkovich, V.P.; Andres, M.V. Nonlinear transmission coefficient of ytterbium-holmium fiber at the wavelength $978 \mathrm{~nm}$. Laser Phys. 2007, 17, 71-79. [CrossRef]

27. Kir'yanov, A.V.; Barmenkov, Y.O.; Villegas-Garcia, I.L.; Cruz, J.L.; Andres, M.V. Highly Efficient Holmium-Doped All-Fiber $\sim 2.07-\mu \mathrm{m}$ Laser Pumped by Ytterbium-Doped Fiber Laser at $\sim 1.13 \mu \mathrm{m}$. IEEE J. Sel. Top. Quantum Electron. 2018, 24, 1-8. [CrossRef]

28. Sumetsky, M. Mode localization and the Q-factor of a cylindrical microresonator. Opt. Lett. 2010, 35, 2385. [CrossRef]

29. Roselló-Mechó, X. Whispering Gallery Modes: Advanced Photonic Applications. Ph.D. Thesis, University of Valencia, Valencia, Spain, 2019.

30. Kir'yanov, A.V.; Barmenkov, Y.O.; Garcia, I.V. $2.05 \mu \mathrm{m}$ holmium doped all-fiber laser diode-pumped at 1.125 $\mu \mathrm{m}$. Laser Phys. 2017, 27, 085101. [CrossRef]

31. Kamrádek, M.; Aubrecht, J.; Peterka, P.; Podrazký, O.; Honzátko, P.; Cajzl, J.; Mrázek, J.; Kubeček, V.; Kašík, I. Spectroscopic characterization of holmium doped optical fibers for fiber lasers. In Micro-Structured and Specialty Optical Fibres VI; Peterka, P., Kalli, K., Mendez, A., Eds.; SPIE: Bellingham, WA, USA, 2019.

32. Kamrádek, M.; Kašík, I.; Aubrecht, J.; Mrázek, J.; Podrazký, O.; Cajzl, J.; Varák, P.; Kubeček, V.; Peterka, P.; Honzátko, P. Holmium doped optical fibers for efficient fiber lasers. In Micro-Structured and Specialty Optical Fibres VI; Bunge, C.A., Kalli, K., Peterka, P., Eds.; SPIE: Bellingham, WA, USA, 2020.

33. Knight, J.C.; Cheung, G.; Jacques, F.; Birks, T.A. Phase-matched excitation of whispering-gallery-mode resonances by a fiber taper. Opt. Lett. 1997, 22, 1129. [CrossRef]

34. Kenny, R.; Birks, T.; Oakley, K. Control of optical fibre taper shape. Electron. Lett. 1991, 27, 1654. [CrossRef]

35. Wait, J.R. Electromagnetic Whispering Gallery Modes in a Dielectric Rod. Radio Sci. 1967, 2, 1005-1017. [CrossRef]

36. Davis, M.; Digonnet, M.; Pantell, R. Thermal effects in doped fibers. J. Light. Technol. 1998, 16, 1013-1023. [CrossRef] 